\title{
Measurement Correlation between High School Grades with College Student GPA using Pearson Method
}

\author{
Heliza Rahmania Hatta \\ Universitas Mulawarman \\ Samarinda, Indonesia
}

\author{
Nur Rahman Ali Muhti \\ Universitas Mulawarman \\ Samarinda, Indonesia
}

\begin{abstract}
The fellowship is one of the systems used to select new students for their admission to the university using students' grades as measurement methods. Because of an assumption that the higher the score of the report card is directly proportional to the quality when the student is in college level. Moreover, we conducted a correlation study between the grades and Grade Point Average (GPA) using the Pearson method to determine whether there is a correlation between both of them. The correlation value will be searched from the data is the data score of report card based on each semester from the first semester to the fifth semester that will be searched the score of the correlation coefficient with GPA. The results of this study concluded that the score of the report card is positively correlated to GPA student but having a different correlation level for each semester.
\end{abstract}

\section{Keywords—high school grades; GPA; college student}

\section{INTRODUCTION}

The fellowship is one of the systems used for the selection of new students who will continue their education from high school to the top level, namely the college. The selection system by using the fellowship is not through a series of tests, but by using grades as a benchmark for selection.

Report card grades which are a recapitulation of student learning outcomes in schools is assumed as a reference point whether the students can follow the lessons. Therefore, the higher the grades then the students will be able to follow the teachings, these assumptions were used in predicting that the student will also work well if continuing education to college. Within the scope of a college student is successful if it has a high-Grade Point Average(GPA) which close to 4 .

The parameters such as the grade report card were used as a benchmark for selection is the report grades. Each of the semester from the semester one to the semester of five during their school years, then for the value of the report card is the basis for the selection of college entrance through the fellowship it is necessary to study whether the value the report card has a positive correlation with the GPA. The positive correlation symbolises that grades important if used as a benchmark in the selection of new college student acceptance through fellowship.

Previous research studies have been conducted to measure the degree of correlation between the national test scores and GPA of Graduate Students applying artificial neural networks (ANN), the results of these studies indicate that the neural network can map the composition of the national test scores and academic achievements of graduates [1]. Further studies have been conducted to measure the degree of correlation of student achievement, by finding the relationship between the value of the final examination (UN) with GPA using backpropagation method which is based on the assumption that the higher value end of the last UN expected to be more ready and able to enroll in college and learning achievement will be higher, The study resulted in the conclusion that the final examination and age is not always used as a benchmark to get the best student graduates or produce students who excel [2]-[4].

In this correlation analysis study, parameters that are used is report grades from the first semester until the fifth semester and student GPA. The assessment is based on the calculation results of the process parameters calculation applying the method of Pearson with input in the form of grades in the variable $x$ and GPA of the variable $y$. From the results of this correlation can be seen that if grades correlate with the GPA, as well as the correlation value can be positive or negative according to the correlation value is generated in the study.

\section{LITERATURE REVIEW}

Correlation analysis is a statistical analysis technique, which is included in the bivariate analysis because it involves the relationship between two variables, correlation analysis purpose was to find out whether there is a relationship between two variables, and if there is a relationship, how the direction of the relationship and how much the relationship. Theoretically, two variables cannot relate at all $(R=0)$, correlate perfectly $(R=1)$, or between these two numbers. Directions can also be a positive correlation (corresponding 
unidirectional) or negative correlation (different directions) [5], [6].

In general, the size of the relationship expressed by numbers. Numbers stating the size of this relationship is called coefficient of correlation or correlation coefficient. The correlation coefficient ranged between 0.00 and +1.00 (positive correlation) or between 0.00 to -1.00 (negative correlation), depending on the direction of a positive or negative relationship. Marked positive coefficient indicates that the guidance of the correlation is positive, and the negative sign coefficient which indicates the direction a negative correlation. While the coefficient which is worth 0.00 indicates no correlation between the variables $x$ and $y$. The correlation coefficient $(R)$ can be determined with an analogy of equation 1 [7]-[9]:

$$
R_{x y}=\frac{N \cdot \sum x i \text { yi }-\left(\sum x i\right) \cdot\left(\sum y i\right)}{\sqrt{N \sum x i^{2}-\left(\sum x i\right)^{2}} \sqrt{N \sum y i^{2}-(\Sigma y i)^{2}}}
$$

Where $R x y=$ Correlation coefficients between the variables $x$ and $y ; x i=$ deviation from the mean for the value of the variable $x ; y i=$ deviation from the average for the value of the variable $y ; N=$ the sum of all the data; $\sum x . y=$ Number multiplication between the variable value $x$ and $y$. Interpretation of the value of the sample correlation value between variables can be classified in Table 1 .

TABLE I. CORRELATION COEFFICIENTS AND THE INTERPRETATION

\begin{tabular}{|l|l|}
\hline Correlation coefficients $(\mathbf{R})$ & \multicolumn{1}{c|}{ Interpretation } \\
\hline $0.00-0.09$ & Ignored correlation \\
$0.10-0.29$ & Weak correlation \\
$0.30-0.49$ & Moderate correlation \\
$0.50-0.70$ & Strong correlation \\
$>0.70$ & Very strong correlation \\
\hline
\end{tabular}

\section{RESULT AND DISCUSSION}

\section{A. Results}

The data used in this study was obtained by performing the process of observation to Mulawarman University students who have taken at least three semesters. Data obtained in the form of grades when students in High School, and data GPA for the semester one to semester three.

The initial stage in the development process of this system is the collection of data and identification of problems of correlation analysis that will be built into the system. The data used is the first-semester report cards until the fifth semester as a variable $x$ and GPA of students drawn at random as a variable $y$, with a total of 50 correspondents. Calculation of each six months $(x)$ with a GPA $(y)$ using Pearson method, which uses equation. The results show the parson method

$$
\mathrm{R}=0.35
$$

Where $R x y=$ Correlation coefficients between the variables students high schools grade and students $G P A ; x i=$ deviation from the mean for the value of the variable students high schools is $3.1 ; y i=$ deviation from the average for the value of the variable GPA is $2.75 ; N=$ the sum of all the data is 50 students ; $\sum x . y=$ Number multiplication between the variable value students high schools and GPA. Interpretation of the value of the sample correlation value between variables can be classified in Table 1 .

A correlation coefficient $(R)$ in every semester with a GPA that is associated with Table 1 has obtained. It is in semester 1, 2 , and 5 had a moderate positive correlation, while semesters 3 and 4 have value 0.23 which means a weak positive correlation. Therefore semester grades can affect GPA. But this is not absolute because it can change the grade, either in high school or college that is influenced by external factors or other factors.

\section{B. Discussion}

Education applied at all levels of qualification, including universities (in this case learning comparison value of lesson in Mulawarman University Study Program should refer to [10] on Indonesian National Qualification Framework. In Article 1 Paragraph 1 of this Presidential Regulation, which is meant by "Indonesia National Qualification Framework, here in after abbreviated (KKNI) as a standard qualification, is a framework of competence qualification that can match, equalize and integrate between the field of education and the field of job training and work experience in the framework of granting recognition of work competence in accordance with the structure of work in various sectors. "In other words, any curriculum applied at the level of qualification (from high school to college), also of course refers and refers to this KKNI. The qualification level for the competencies mentioned in Figure 1.

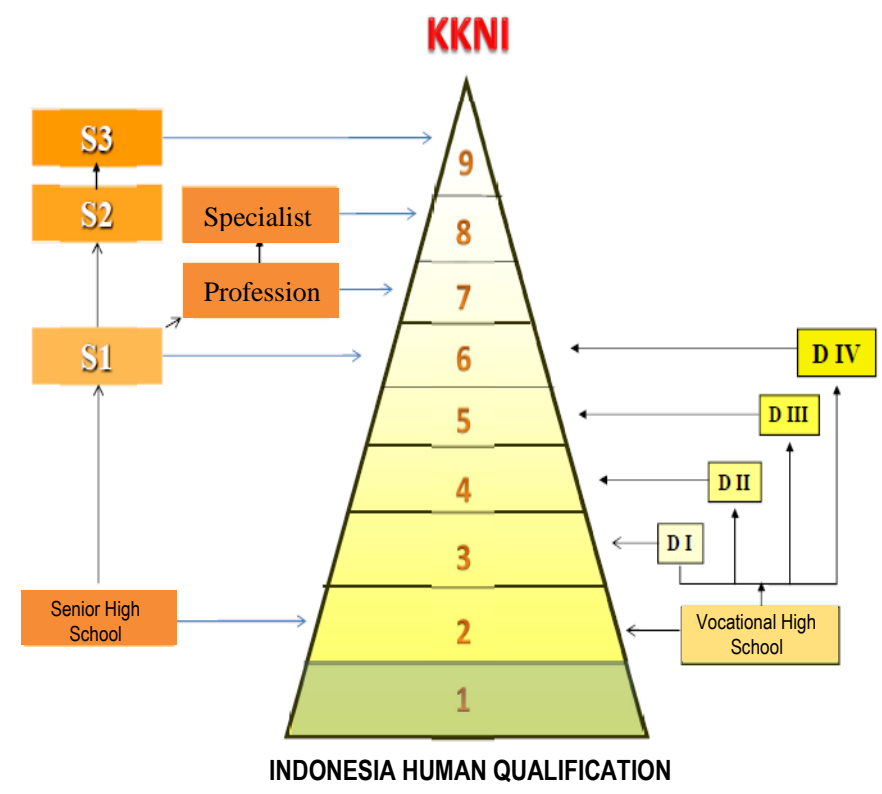

Fig. 1. Qualification Competency

The level of qualification of the competency shown in [11] in Figure 1, especially at Level 6 (for Undergraduate and D4) essentially includes four things: (1) being able to utilize science, technology and science ) in the area of expertise, and 
able to adapt to the situation faced in solving the problem; (2) mastering the theoretical concepts of specialist and in-depth knowledge field in certain fields, and able to formulate problem-solving procedural; (3) capable of making strategic decisions based on the analysis of information and data, and providing guidance in choosing various alternative solutions; and (4) are responsible for their work and may be held accountable for the achievement of the organization's work.

Quality learning is highly dependent on student motivation and lecturer creativity. Students who have high motivation supported by lecturers who can facilitate the motivation will lead to the achievement of learning targets. Learning goals can be measured through changes in student attitudes and abilities through education. Good learning design, supported by adequate facilities, coupled with the creativity of lecturers will make students more easily achieve the target knowledge. Therefore, [12] asserted that the success in teaching and learning depends on the ability of lecturers in planning, which includes among others determining student learning goals, how to make the students achieve the target, what means required, etc., as a system or learning process.

It is reasonable that [13] was expected learning process is a process that can develop students' potentials in a holistic and integrated manner. The development of individual dimensions partially will not be able to support the optimisation of potential student development as expected be done. Therefore, in the process of learning, lecturers are not only required to deliver teaching materials but must be able to actualise its strategic role in the effort to shape the character of students through the development of personality and values that apply. In the preparation of learning materials, [14] requires that refers to the purpose of the by considering the stage of development and the needs that exist today. Therefore, teaching materials need to be prepared carefully by integrating knowledge of environment with sustainable development concept, and compiled comprehensively, and easily applied to all target groups (students). Substantively, as affirmed [13], the direction of education and learning should be able to equip students with cross-curriculum curriculum competencies that are directed at the ability to solve problems, communication, social and interpersonal relationships, independence, ethics and aesthetics that must obtained holistically and integrative through the learning process. Also, additional education is requiring for students, as evidenced by the results of [15] research, conclusion tools can always simulate that other learning in encouraging the development of student potential.

\section{CONCLUSION}

Based on the research results can be concluded that the grades positively correlated to the GPA student and from this study can see that the actual value of report cards is one factor that can use as a benchmark in the selection of new admissions by using the fellowship. But the correlation only a moderate correlation with the largest correlation value is $R=0.3647$ in the calculation of the 2 nd half, with values only ranged in correlation were then this conclusion is not absolute because the grade can change either in high school or colleges that influenced by external factors or other factors.

\section{References}

[1] C. Stevens, B. Lauinger, and H. Neville, "Differences in the neural mechanisms of selective attention in children from different socioeconomic backgrounds: an event- related brain potential study," Dev. Sci., vol. 12, no. 4, pp. 634-646, 2009.

[2] M. J. Schmoker, The results fieldbook: Practical strategies from dramatically improved schools. ASCD, 2001.

[3] J. O'Flaherty and C. Phillips, "The use of flipped classrooms in higher education: A scoping review," Internet High. Educ., vol. 25, pp. 85-95, 2015 .

[4] M. Baba-Djara et al., "Using what you have to get what you want": Vulnerability to HIV and prevention needs of female post-secondary students engaged in transactional sex in Kumasi, Ghana A qualitative study," Ghana. January, 2013.

[5] R. W. Ogden, "Large deformation isotropic elasticity-on the correlation of theory and experiment for incompressible rubberlike solids," in Proceedings of the Royal Society of London A: Mathematical, Physical and Engineering Sciences, 1972, vol. 326, no. 1567, pp. 565-584.

[6] J. R. Edwards and R. P. Bagozzi, "On the nature and direction of relationships between constructs and measures.," Psychol. Methods, vol. 5, no. 2, p. $155,2000$.

[7] R. J. Allemang and D. L. Brown, “A correlation coefficient for modal vector analysis," in Proceedings of the 1st international modal analysis conference, 1982, vol. 1, pp. 110-116.

[8] C. Fornell and D. F. Larcker, "Evaluating structural equation models with unobservable variables and measurement error," J. Mark. Res., pp. 39-50, 1981.

[9] H. Hotelling, "Analysis of a complex of statistical variables into principal components.," J. Educ. Psychol., vol. 24, no. 6, p. 417, 1933.

[10] P. R. Indonesia, "Peraturan Presiden Republik Indonesia Nomor 8 tahun 2012 tentang Kerangka Kualifikasi Nasional Indonesia,” Setneg Jakarta Lembaran Negara Republik Indones., 2012.

[11] I. V. R. Sitepu, "Competencies of higher education graduates: A case of universitas Kristen Indonesia.” Universitätsbibliothek Kassel, 2011

[12] E. F. Barkley, K. P. Cross, and C. H. Major, Collaborative learning techniques: A handbook for college faculty. John Wiley \& Sons, 2014.

[13] A. Aunurrahman, F. Abdul Hamied, and E. Emilia, "Facilitating Character Building through an Academic Writing Practice," 2016.

[14] A. Amirudin, B. Handoyo, and H. Soekamto, "CHARACTERISTICS OF DESASTER PRE LIMINARY RE-SEARCH IN DEVELOPING LEARNING MODEL OF ENVIRON-MENT EDUCATION BASED ON THE DISASTER IN EFFORD TO GROW AN CULTURAL ANTICIPATORY,” J. Pendidik. Geogr., vol. 20, no. 1, 2016.

[15] Z. Gao, S. Jain, F. Stephan, and S. Zilles, "A survey on recent results on partial learning," in Proceedings of the Thirteenth Asian Logic Conference, 2015, pp. 68-92. 